\title{
Computer Aided Design and Analysis of Flywheel
}

\author{
Ashish R. Sonekar' ${ }^{1}$ S. G. Bahaley ${ }^{2}$ \\ ${ }^{1}$ PG Student, Department of Mechanical Engineering, Prof. Ram Meghe Institute of Technology \& Research, Badnera; Amravati India \\ ${ }^{2}$ Professor, Department of Mechanical Engineering, Prof. Ram Meghe Institute of Technology \& Research, Badnera; Amravati India
}

\begin{abstract}
This study solely focuses on exploring the effects of flywheel geometry on its energy storage/deliver capability per unit mass, further defined as specific energy. Various profiles of flywheel are studied and the stored kinetic energy is calculated for the respective flywheel. Various profiles designed are solid disk, rim type, webbed/section cut flywheel. It shows that smart design of flywheel geometry could both have a significant effect on the Specific Energy performance and reduce the operational loads exerted on the shaft/bearings due to reduced mass at high rotational speeds. Efficient flywheel design used to maximize the inertia of moment for minimum material used and guarantee high reliability and long life. FE analysis is carried out for different cases of flywheel and maximum von mises stresses and total deformation are determined. The present work deals with the problem of weight minimization and energy maximization of flywheel. We take press machine flywheel and analyze it using ANSYS (finite element modeling and analysis software) to optimize weight and find out the resulting stresses. Also we compare the theoretical stress results with analysis software stress results and suggest smart profile of flywheel so it can store more amount of energy than solid disk flywheel.
\end{abstract}

Keywords: Flywheel, specific energy, stored kinetic energy, stress analysis, FE analysis

\section{Introduction}

Flywheel acts as a reservoir by storing energy during the period when the supply of energy is more than the requirement and releasing it during the period when the requirement of the energy is more than the supply. Flywheel provides an effective way to smooth out the fluctuation of speed. The stored kinetic energy relies on the mass moment of inertia and rotational speed. . A flywheel is a mechanical device with a significant moment of inertia used as a storage device for rotational energy. Flywheels resist changes in their rotational speed, which helps steady the rotation of the shaft. Flywheels have become the subject of extensive research as power storage devices for uses in vehicles. Flywheel energy storage systems are considered to be an attractive alternative to electrochemical batteries due to higher stored energy density, higher life term, and deterministic state of charge and ecologically clean nature. The performance of a flywheel can be attributed to three factors, i.e., material strength, geometry (cross- section) and rotational speed.

\section{A. Material strength}

Stronger materials could undertake large operating stresses, hence could be run at high rotational speeds allowing storing more energy. Hence could be run at high rotational speeds allow wing to store more energy.

\section{B. Rotational speed}

It directly controls the energy stored, higher speeds desired for more energy storage, but high speeds assert excessive loads on both flywheel and bearings during the shaft design.

\section{Geometry}

It controls the Specific Energy, in other words, kinetic energy storage capability of the flywheel. Any optimization effort of flywheel cross-section may contribute substantial improvements in kinetic energy storage capability thus reducing both overall shaft/bearing loads and material failure occurrences. Flywheel efficiency includes the amount of specific kinetic energy (energy per unit mass) and mechanical losses.

To improve the quality of the product and in order to have safe and reliable design, it is necessary to investigate the stresses induced in the component during working condition. When the flywheel rotates, centrifugal forces acts on the flywheel due to which tensile and bending stress are induced in a rim of flywheel. To counter the requirement of smoothing out the large oscillations in velocity during a cycle of a mechanism system, a flywheel is designed, optimized and analyzed. By using optimization technique various parameter like material, cost for flywheel can be optimized and by applying an approach for modification of various working parameter like efficiency, output, energy storing capacity, we can compare the result with existing flywheel result.

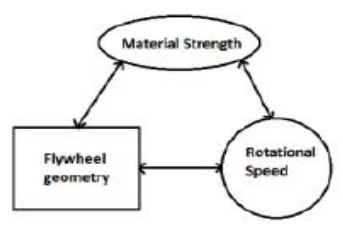

Figure 1 : Relation between attribute factors

\section{Geometrical Dimensions of Flywheel}

Flywheel used in the press machine is solid disk. Dimensions of flywheel are provided below. This flywheel is designed and analyzed.

Mass of flywheel $(\mathrm{m})=100 \mathrm{~kg}$.

Outer diameter of flywheel (do) $=662 \mathrm{~mm}$.

Inner diameter of flywheel (di) $=50 \mathrm{~mm}$.

$\operatorname{Rpm}(\mathrm{n})=1310$

\section{Material for Flywheel}

CAST IRON, ASTM 30, SAE 111

Density $=7510 \mathrm{~kg} / \mathrm{m}^{3}$

Poisons ratio $(v)=0.23$ 
Modulus of elasticity = $101 \mathrm{Gpa}$

Modulus of rigidity $=41 \mathrm{Gpa}$

Torsional/shear strength=276 Mpa

Table 1 : Functional Values of Solid Flywheel

\begin{tabular}{|c|c|c|c|c|c|}
\hline Type & $\begin{array}{c}\text { Mass of } \\
\text { Flywheel } \\
\mathrm{Kg}\end{array}$ & $\begin{array}{c}\text { Moment of } \\
\text { inertia(I) } \\
\text { Kg-m }\end{array}$ & $\begin{array}{c}\text { Kinetic } \\
\text { energy } \\
\text { stored } \\
(\Delta \mathrm{E}) \mathrm{KJ}\end{array}$ & $\begin{array}{c}\text { Spe. } \\
\text { Energy } \\
\mathrm{KJ} / \mathrm{kg}\end{array}$ & $\begin{array}{c}\text { Spe. Density } \\
\mathrm{KJ} / \mathrm{m}^{3}\end{array}$ \\
\hline Solid & 100 & 7.241 & 68.133 & 0.63615 & 4777.549 \\
\hline
\end{tabular}

\section{Other Flywheel Geometries}

Other flywheel geometries taken under study are rim type, webbed/ section cut; keeping constant outside diameter 662 $\mathrm{mm}$ and varies the mass, stored kinetic energy is calculated for these profiles. This study clearly depicts the importance of flywheel geometry design selection and its contribution in the energy storage performance. Although this improvement is to be thought small, it still could be crucial for mission critical operations. Other profiles of flywheel given below are designed and analyzed.
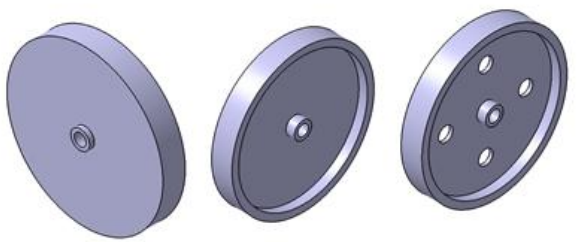

Figure 2 : Various Profiles of Flywheel

Table 2: Comparison of Functional Values of Flywheel

\begin{tabular}{|c|c|c|c|}
\hline Functional values & Solid & Rim & $\begin{array}{c}\text { Webbed/ } \\
\text { Section Cut }\end{array}$ \\
\hline Moment of inertia(I)Kg-m ${ }^{2}$ & 7.241 & 2.3686 & 2.3678 \\
\hline Kinetic energy $(\Delta \mathrm{E})$ stored KJ & 68.133 & 22.287 & 22.279 \\
\hline Spe. Energy KJ/kg & 0.63615 & 0.54359 & 0.5592 \\
\hline Spe. Density $\mathrm{KJ} / \mathrm{m}^{3}$ & 4777.549 & 4082.36 & 4199.81 \\
\hline
\end{tabular}

\section{Finite Element Analysis of Flywheel}

These three profiles of flywheel used are analyzed by FE software i.e. ANSYS software. FE analysis is carried out for different cases of loading applied on flywheel and maximum von mises stresses and total deformation are determined.

Loading condition: - Angular velocity
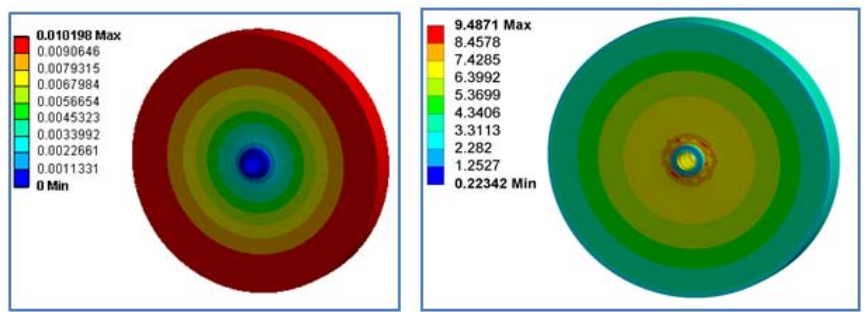

Figure 3: Analysis of Solid Flywheel

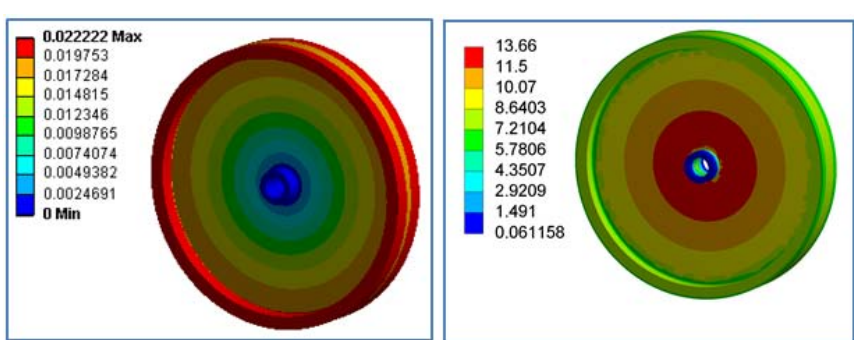

Figure 4: Analysis of Rim Type Flywheel

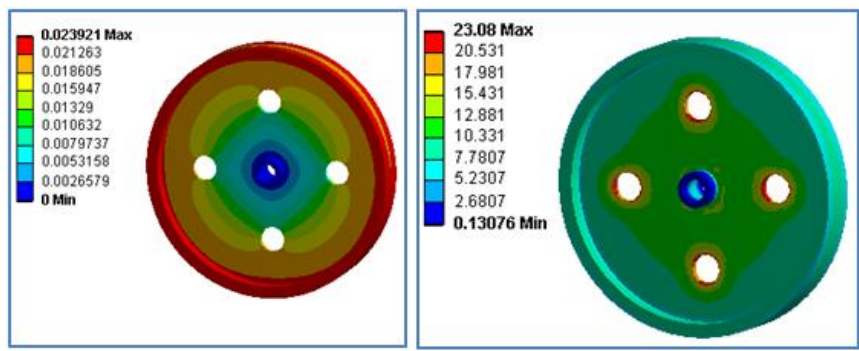

Figure 5: Analysis of Webbed/Section Cut Flywheel

Table 3: Comparison of Analysis of Flywheel

\begin{tabular}{|c|c|c|c|c|}
\hline $\begin{array}{c}\text { Type of } \\
\text { Flywheel }\end{array}$ & $\begin{array}{c}\text { Load } \\
\text { (Angular } \\
\text { velocity) } \\
(\omega \mathrm{rad} / \mathrm{sec})\end{array}$ & $\begin{array}{c}\text { Mass } \\
(\mathrm{Kg})\end{array}$ & $\begin{array}{c}\text { Equi. Von } \\
\text { mises } \\
\text { stresses } \\
(\mathrm{Mpa})\end{array}$ & $\begin{array}{c}\text { Total } \\
\text { Deformation } \\
(\mathrm{mm})\end{array}$ \\
\hline Solid & 137.182 & 100 & 9.4871 & 0.010198 \\
\hline Rim Type & 137.182 & 41 & 13.66 & 0.022222 \\
\hline $\begin{array}{c}\text { Webbed/ } \\
\text { Section Cut }\end{array}$ & 137.182 & 39.84 & 23.08 & 0.023921 \\
\hline
\end{tabular}

\section{Conclusions}

In this paper we work on to minimize the mass of solid disk flywheel by suitable optimization method so that it can store same amount of energy as that of original flywheel and also to suggest smart profile of flywheel so it can store more amount of energy than solid disk flywheel. Also, we deal with the three different flywheels such as solid disc, rim type and section cut flywheel, we design the flywheel by using energy method and to determine varies stresses induced in it. For this work finite element approach can effectively use to study analysis of three different flywheels to optimize weight and find out the resulting stresses. Compare analysis software stress results, we can say that in section cut flywheel mass is less as compare to other two flywheel (i.e. mass of section cut flywheel $39.84 \mathrm{~kg}$.). Also theoretical stress and analysis stress values are less than design stress value so design is safe. So section cut flywheel is suitable for press machine.

\section{References}

[1] Sushama G Bawane , A P Ninawe and S K Choudhary, Analysis and optimization of flywheel, International Journal of Mechanical engineering and robotics Vol. 1, No. 2, July 2012.

[2] S. M. Dhengle, Dr. D. V. Bhope, S. D. Khamankar , Investigation of stresses in arm type rotating flywheel, International Journal of Engineering Science and Technology (IJEST), Vol. 4 No.02 February2012.

[3] Akshay P. Punde, G.K.Gattani ,Analysis of Flywheel, International Journal of Modern Engineering Research 
(IJMER) , Vol.3, Issue.2,March-April. 2013 pp-10971099.

[4] Sudipta Saha, Abhi Bose, G. Sai Tejesh, S.P. Srikanth , computer aided design \& analysis on flywheel for greater efficiency, International Journal of Advanced Engineering Research and Studies, IJAERS/Vol. I/ Issue II/January-March, 2012/299-301.

[5] M.lavakumar, R.Prasanna Srinivas, Design and analysis of lightweight motor vehicle flywheel, International Journal of Computer Trends and Technology (IJCTT) volume 4 Issue -7July 2013.

[6] Sushama G Bawane , A P Ninawe and S K Choudhary, Analysis and optimization of flywheel, International Journal of Mechanical engineering and robotics Vol. 1, No. 2, July 2012.

[7] D.Y. Shahare, S. M. Choudhary , Design Optimization of Flywheel of Thresher using FEM, Advanced Materials Manufacturing \&Characterization Vol3 Issue 1 (2013). 